\title{
O retratista e os intelectuais às voltas com 1964
}

\author{
Anderson Gonçalves ${ }^{1}$, Edu Teruki Otsuka² e Ivone Daré Rabello ${ }^{3}$
}

\begin{abstract}
SCHWARZ, Roberto. Martinha versus Lucrécia.
São Paulo: Companhia das Letras, 2012, 320 p.
\end{abstract}

Martinha versus Lucrécia (ensaios e entrevistas), de Roberto Schwarz, publicado em $2012^{4}$, atiçou, de imediato, o espírito rixoso de setores conservadores de nossa crítica cultural que, diante da crítica materialista, não se cansam de detratá-la, porque, segundo eles, as questões histórico-sociais não seriam próprias à literatura, e, assim, não caberia à crítica literária interpretar o Brasil, tarefa para sociólogos e historiadores ${ }^{5}$. Outros, ainda, fizeram do ensaio sobre Caetano Veloso a pedra de toque da contenda, pretendendo denunciar, não sem satisfação, posições retrógradas de Schwarz, supostamente incapaz de entender as razões estéticas da obra de um ícone da música brasileira, além de estar quinze anos atrasado $^{6}$. No outro campo da peleja, houve pelo menos uma eficiente

I Professor do Departamento de Teoria Literária e Literatura Comparada da Faculdade de Filosofia, Letras e Ciências Humanas da Universidade de São Paulo.

E-mail: andergon@usp.br

2 Professor Doutor do Departamento de Teoria Literária e Literatura Comparada da Faculdade de Filosofia, Letras e Ciências Humanas da Universidade de São Paulo, com graduação em Letras, mestrado em Teoria Literária e Literatura Comparada e doutorado em Literatura Brasileira pela USP. E-mail: eduotsuka@usp.br

3 Professora aposentada do Departamento de Teoria Literária e Literatura Comparada da Faculdade de Filosofia, Letras e Ciências Humanas da Universidade de São Paulo. Possui graduação em Bacharel em Letras Português Francês pela Universidade de São Paulo (1974), mestrado e doutorado em Teoria Literária e Literatura Comparada pela Universidade de São Paulo.

E-mail: ivonedare@uol.com.br

4 Doravante MvL. A obra reúne textos já publicados ao longo dos anos 2001 a 2011, com exceção do inédito "Verdade tropical: um percurso de nosso tempo", de 2011, e de "Por que 'ideias fora do lugar'?", palestra de 2009.

5 Ver a resenha de ASCHER, Nelson. O crítico justiceiro. Veja, p. 138-139, 2 maio 2012.

6 Ver GONÇALVES, Marcos Augusto. Feitiço tropical - Schwarz versus Caetano. Folha de S.Paulo, 15 abr. 2012; e WISNIK, José Miguel. Versus. O Globo, 28 abr. 2012. 
exposição sumária da obra, em que se descrevem e se interpretam alguns dos principais temas da produção do crítico ${ }^{7}$. A desproporção das opiniões difundidas é significativa não apenas da estreiteza do debate, mas também do domínio, na crítica cultural brasileira, da tentativa de neutralizar questões decisivas para se compreenderem a cultura e a história recentes, bem como a iluminação entre uma e outra. O fenômeno, bem conhecido, evidencia o que está de fato em jogo, a saber, o ocultamento ou a revelação de como a literatura e a crítica capturam a experiência comum em sua dimensão histórica. No entanto, uma vez que o crítico dialético procura o substrato conflitivo das obras e, assim, busca e provoca enfrentamentos, como poderia ser de outro modo no anêmico cenário contemporâneo?

A obra ensaística de Schwarz se distingue pela reflexão constante sobre problemas da cultura em que estão inscritos aspectos estruturais da sociedade brasileira. Ao lado dos trabalhos indispensáveis sobre Machado de Assis, em que a investigação estética levou o crítico a elucidar a dinâmica específica da formação histórica do Brasil e seus efeitos na vida cultural do país, e do estudo sobre Helena Morley, em Duas meninas (1997), em que a análise de um diário sem intenções literárias permitiu compreender a reacomodação dessegregadora das relações sociais brasileiras em circunstâncias bastante especiais e irrepetíveis, os ensaios mais curtos compõem no conjunto um painel, impressionante pela agudeza, da cultura brasileira contemporânea. Desde O pai de família (1978), passando por Que horas são? (1987) e Sequências brasileiras (1999), até Martinha versus Lucrécia (2012), cada coletânea, cobrindo mais ou menos uma década, apresenta estudos decisivos para a compreensão de vários momentos da história e da cultura brasileiras. Os ensaios retomam e desdobram em múltiplos âmbitos questões associadas ao eixo da interpretação histórico-social do Brasil apresentada extensamente através da obra machadiana, indicando a renitência de um núcleo de problemas insuperados e incessantemente, repostos pelo modo como a sociedade se reproduz. Ao mesmo tempo, destrincha as configurações particulares em que aqueles problemas são reelaborados em obras literárias e cinematográficas, projetos estéticos e políticos, posições intelectuais e ideológicas, conforme se alteram as circunstâncias econômicas e políticas nacionais e internacionais, o jogo de forças sociais em embate ou em aliança, as expectativas de progresso e integração etc.

7 Ver OHATA, Milton. Progresso à moda brasileira. Piaui, n. 69, p. 70-72, jun. 2012. 
A contundência da crítica de Schwarz, firmemente fundada numa perspectiva de esquerda, é notável, e algo do tom dos ensaios de cada livro parece responder ao ambiente político geral de cada momento o período pós-1964 da ditadura militar (em que a produção cultural de esquerda mudava de rumo em relação aos anos anteriores ao golpe), o tempo de abertura política e perspectiva de redemocratização (também com o surgimento do Partido dos Trabalhadores na cena política), as promessas espúrias de um salto integrador na abertura para o mercado internacional (anos Collor), o desenlace decepcionante da chegada da antiga esquerda ao poder.

Schwarz procede com o tino do ensaísta que escreve com liberdade de espírito sobre os mais variados objetos, os quais elege conforme as circunstâncias e a intuição certeira. Além da discussão que imediatamente provocam, os textos resultantes, quando reunidos em livro, não raro têm sua força potencializada, na medida em que, no conjunto, o debate de ideias, o comentário histórico-sociológico e a crítica estética, longe de se retraírem em seus nichos, configuram problemas que se cruzam, uns sobre os outros, compondo panoramas complexos dos momentos que acompanharam, suscitando reflexão. Esse resultado é alcançado talvez porque o motor dos ensaios schwarzianos não é a servidão acadêmica, mas sim a análise da atualidade, feita com a convicção política de quem não quer colaborar na perpetuação do existente.

Tal é, especialmente, o caso de Sequências brasileiras, que parecia mesmo apontar para um limiar histórico a ser transposto pela crítica brasileira, a qual até então havia se movido nos limites de uma tradição de pensamento circunscrita no quadro nacional, que a obra de Schwarz levou até seu último desdobramento. Frente ao contexto de mudanças que se iniciavam naqueles anos 1990 - e que se consolidaram nos anos seguintes -, os textos desse livro eram como a ponta de lança que forneceu base e inspiração para inúmeros intelectuais que tencionaram avançar no exame das "coisas novas e ruins" do presente, gerando tópicos e programas de estudo ${ }^{8}$.

Instigado pela leitura de O colapso da modernização(1991), de Robert Kurz, em que o sociólogo alemão analisa o rumo do sistema capitalista recolhendo os sinais de esgotamento do ciclo histórico da modernização e o desmanche da sociedade do trabalho, Schwarz valeu-se do diagnóstico sobre as "sociedades pós-catástrofe" e articulou a experiência brasileira

8 Esse é notadamente o caso do Nedic (hoje Cenedic), fundado em 1995. Ver OLIVEIRA, Francisco de. Um crítico na periferia do capitalismo. In: CEVASCO, Maria Elisa; OHATA, Milton (org.). Um crítico na periferia do capitalismo: reflexões sobre a obra de Roberto Schwarz. São Paulo: Companhia das Letras, 2007. p. 149. 
(constantemente ameaçada de recair na irrelevância) ao curso do mundo contemporâneo, pondo à mostra na vida periférica uma atualidade cuja verossimilhança era garantida pela confluência das modernizações, a abortada e a consumada, que convergiam na tendência geral à desagregação. Quaisquer que sejam os acertos ou os limites da teoria de Kurz, era essa nova situação histórica que rondava a inquietação de Schwarz nos ensaios de Sequências brasileiras ${ }^{9}$.

Diante desse cenário de devastação, em que os novos padrões produtivos se tornaram inalcançáveis para os países como o Brasil, interrompendo o ciclo da industrialização e as promessas a ela atreladas, Schwarz formula, pela primeira vez, as consequências do esgotamento definitivo do nacional-desenvolvimentismo, que havia impulsionado a intelectualidade brasileira dos anos 1930 aos anos 1980, tendo aguçado a percepção dos problemas sociais do país e, ao mesmo tempo, limitado o alcance crítico do pensamento aqui produzido. Constatava-se nos textos de Sequências o fechamento de um ciclo, cuja tônica havia sido dada pela tarefa inconclusa da integração nacional, e o início de uma era em que o quadro de certezas do período anterior foi desestabilizado na raiz. Por isso, Schwarz insiste no caráter ilusório da ideia de modernização que vigorara no período agora encerrado e que era "estreita e provinciana", pois para ela "o problema não estava na marcha do mundo, mas apenas em nossa posição relativa dentro dela"10. A constatação dos limites do ciclo mental anterior fez Schwarz notar, e também pela primeira vez formular com todas as letras, o (auto)confinamento a que se impôs o marxismo uspiano que, ao menos para os paulistas, passava por ser a ponta avançada da produção intelectual de esquerda no país, e que, sem prejuízo de ter gestado uma nova intuição histórico-sociológica do Brasil, acabou se revelando um marxismo de corte industrializante.

O avanço do capitalismo, assim, impunha uma desqualificação maciça da experiência anterior, deitando por terra as derradeiras expectativas de integração futura, e a novidade do ciclo que se abria sob o signo da desagregação começava a se manifestar concretamente na vida cotidiana. No novo contexto, de recuo da luta de classes, os abandonados pela industrialização interrompida ("ex-proletários virtuais", na expressão de Kurz) encontravam modos de reinserção social por via da criminalidade, do tráfico de drogas, das contravenções e conluios traços apreendidos pela literatura, notadamente Estorvo (1991), de Chico

9 Além dos textos incluídos em SCHWARZ, R. Sequências brasileiras. São Paulo: Companhia das Letras, 1999. ("O livro audacioso de Robert Kurz", especialmente), ver idem, Ainda o livro de Kurz. Novos Estudos Cebrap, n. 37, p. 133-137, nov. 1993.

1o SCHWARZ, R. Fim de século. In: . Sequências brasileiras. op. cit., p. 161. 
Buarque, e Cidade de Deus (1997), de Paulo Lins, cuja força de revelação sobre o presente Schwarz identificou e pôs "por escrito e para uso do próximo" (para usar os termos do crítico a propósito de Kurz ${ }^{11}$ ).

Nesse quadro de mudanças históricas, com os “deslocamentos ciclópicos"12 operados pelo capital global, Schwarz lançava uma avalanche de perguntas decisivas, explícitas ou não, no esforço de compreender a reviravolta então em curso, que desestabilizava convicções e esquemas explicativos. Com efeito, a desagregação refluía sobre as próprias categorias que haviam balizado toda a tradição crítica anterior, cujo sentido e destino cumpria examinar à luz da atualidade: o que pensar da modernização, agora sem compromisso com a integração do país? "O que significa uma cultura nacional que já não articule nenhum projeto de vida material"13? O que fazer com a ideia de formação, que no plano cultural se completou, sem ter sido acompanhada da formação nacional a que estava atrelada? Como entender o engajamento, agora generalizado e voltado ao governo, à administração pública e à gestão do capital? Qual a eficácia da crítica apoiada no desnudamento das razões econômicas, hoje ideologia explícita das classes dominantes para justificar a desigualdade social? Qual o lugar da luta de classes, agora que "a crise do capitalismo se aguça no momento mesmo em que a classe operária já não tem força para colher os seus resultados"14? Tais eram algumas das inquietações nos ensaios do livro anterior, que, sem nenhuma menção explícita à era Fernando Henrique Cardoso e à sua guinada neoliberal, tratava também das mudanças postas em curso pelo presidente à época ${ }^{15}$.

Era natural, pois, que, pelo menos para uma parte de seus leitores, fosse grande a expectativa em relação aos escritos subsequentes de Schwarz. Novos textos foram aparecendo, mas nenhum, isoladamente, provocou efeitos equivalentes aos de "Fim de século" ou "Nunca fomos tão engajados" (ambos de 1994, depois recolhidos em Sequências brasileiras). Reunidos nessa coletânea de 2012, porém, ganham significados que é preciso investigar. O leitor de Sequências, instruído sobre os impasses do presente, aguardava o prosseguimento das considerações sobre a última década e seu anseio parece ter sido frustrado por não

11 Idem, O livro audacioso de Robert Kurz. In: Sequências brasileiras. op. cit., p. 187.

12 Idem, Nunca fomos tão engajados. In: Sequências brasileiras. op. cit., p. 177.

13 Idem, Fim de século. In: Sequências brasileiras. op. cit., p. 162.

14. Idem, O livro audacioso de Robert Kurz. In: Sequências brasileiras, op. cit., p. 186.

15 No entanto, cabe lembrar que em entrevistas Schwarz se manifestou sobre o presidente. Ver "Do lado da viravolta", entrevista concedida a Fernando Haddad e Maria Rita Kehl. Teoria e Debate, n. 27, dez. 1994; "A dialética envenenada de Roberto Schwarz", entrevista concedida a Fernando de Barros e Silva. Folha de S.Paulo, 10 jun. 1997 . 
encontrar continuidade direta das reflexões sobre a atualidade. Em vez disso, Martinha versus Lucrécia, à vista desarmada, dá a impressão de apenas retomar problemas já formulados em ensaios anteriores, comentar o percurso do próprio autor (em duas das entrevistas) e compor uma coleção de retratos de intelectuais de que Schwarz esteve próximo nos anos 1960. No entanto, o desconcerto inicial do leitor exige que ele se lance à atividade da compreensão. Embora os ensaios de Martinha versus Lucrécia sugiram afastamento em relação às urgências do presente, o reexame dos anos em torno de 1964, recorrente nos textos do livro, permite pensar a ditadura como o momento em que se iniciou a contemporaneidade ${ }^{16}$.

Com espírito provocador, Schwarz sugere muitas pistas para que a unidade não evidente desta coletânea seja investigada. Desde o título, insinua-se uma estrutura fundada no litígio. O termo "versus" pressupõe o embate, bem como a contestação de uma demanda (incluída, aí, talvez, a de responder diretamente ao presente). Ao mesmo tempo retoma uma contenda, nossa velha conhecida, a respeito da pendulação entre a valoração do local e do universal, a que estiveram confinados setores de nossa intelectualidade, desde a Independência, e cuja sobrevida, hoje, paira por outros campos, inclusive o da legitimação acadêmica.

A questão é examinada exemplarmente no ensaio de abertura, "Leituras em competição" (2006); trata-se de pensá-la quando o redimensionamento da estima internacional por Machado de Assis põe na ordem do dia os critérios pelos quais se valoriza a obra, com consequências para o ajuizamento sobre as várias correntes atuais da crítica literária, brasileira ou não, em que o estudo da forma, compreendida como resultado estético-social, é objeto de disputas também políticas ${ }^{17}$.

O estado atual das discussões sobre a relação entre centro e periferia, tal como apresentadas em chaves diversas ao longo do livro, indica que ela não mais ordena nenhum horizonte de transformação; antes, apenas reativa anseios particularistas, ou, na outra mão, abstratamente universalistas, ambos ideológicos. Como já demonstrou Schwarz desde seus estudos machadianos, o confronto entre as experiências do centro

16 Em seminário aberto, realizado na FFLCH-USP em 22 de agosto de 2012, com a presença de Roberto Schwarz, Paulo Arantes apresentou a sugestão que aqui se procura desenvolver, segundo a nossa compreensão. Além disso, este texto se beneficia de outras sugestões do professor que, com presteza, discutiu conosco algumas das ideias de versão anterior.

17 A editora se encarregou de adicionar uma ironia objetiva ao estampar na quarta capa do livro as opiniões de dois renomados intelectuais estrangeiros sobre o autor, como a atestar uma consagração internacional de Roberto Schwarz, para brasileiro ver. 
e da periferia pode, nos seus melhores momentos, levar à desqualificação recíproca entre esses polos ${ }^{18}$ e conduz à crítica dirigida a ordem que produz as diferenças: o capitalismo mundial. Sendo esse o objeto último da crítica, a questão nacional, ou localista, é apenas parte do problema mais amplo, referente à sociedade contemporânea. Esse resultado, porém, ainda não foi compreendido pelos detratores que continuam a atribuir ao autor a miopia produzida pelo apego à referência nacional, nem devidamente assimilado de modo consequente por alguns dos que pretendem se alinhar às suas construções teóricas.

Sem alarde, Schwarz trata da experiência de 1964 como quem apreende naquele momento histórico a gênese do nosso presente. A promessa de integração desenvolvimentista, ilusória, e de todo modo perdida, cuja realização parecia iminente entre os anos 1950 e 1960, foi frustrada pela vitória da direita brasileira e pelo curso do capitalismo mundial, do que resultou o completamento do nosso processo de modernização. Aqueles anos 1960, vistos criticamente a partir dos dias que correm, permitem apreender o fechamento de um ciclo político e a abertura de outro, sem que tenha havido transformação efetiva rumo a uma nova ordem. Não à toa, o último ensaio, que se dedica à viravolta machadiana, sugere um prisma, também para examinar o presente, através do qual se revela a permanência de formas acintosas da iniquidade à brasileira (“os proprietários participam intensamente do progresso contemporâneo, mas isso graças às relações antiquadas em que se apoiam, e não a despeito delas, e menos ainda por oposição a elas, como imaginaria o senso comum"19), articuladas a novos mecanismos de dominação.

A reflexão circunscrita ao quadro de relações entre centro e periferia perdeu vigor crítico, e a sobreposição de atraso e progresso como penhor de identidade nacional tornou-se produto de mercado; o anseio pela nação integrada se restringe hoje à boa fortuna dos fundos de pensão dos trabalhadores, ao incremento de programas que diminuem os índices de miserabilidade e à consolidação de uma nova lógica de integração perversa dos pobres ao mundo econômico. O lastro histórico desses fatos se assenta nos anos em que a luta pela transformação foi derrotada. Sem colocar essa matéria ostensivamente em primeiro plano, nem se deter no modo pelo qual os governos mais recentes consumaram o que ali foi gestado, Schwarz esboça retratos de amigos de geração que, escritos em circunstâncias específicas, estão longe de ser simples testemunhos memorialísticos, sugerindo,

18 Schwarz retoma o que Antonio Candido identificou como "uma lei de evolução de nossa vida espiritual", isto é, a "dialética do localismo e do cosmopolitismo", e avança no entendimento dessa dinâmica.

19 MvL, p. 275. 
antes, um jogo de armar em que a constelação das diferentes trajetórias daqueles intelectuais é imantada pela reflexão sobre o destino de ganhadores e perdedores em 1964, bem como sobre as razões das guinadas do ideário da esquerda posteriores a essa data.

Guiando a discussão, paira a proximidade indireta dessas questões com a problemática encenada em "O punhal de Martinha”, de Machado de Assis. Em "Leituras em competição", Schwarz examina o pendor para a polêmica sardônica que anima esse texto machadiano, no qual o cronista que frequenta as rodas modernas do Rio de Janeiro valoriza ambiguamente Martinha, a moça pobre que vive num confim de mundo no Brasil, comparando-a com Lucrécia, da História romana, de Tito Lívio. Dado o disparate, a comparação entre a figura local e a universal, aqui, se tinge com a galhofa. Para destacar o valor heroico de Martinha, o cronista se vale de suas prerrogativas de classe, troça incluída, sublinhando a distância entre ele e seus compatriotas pobres, ainda que deles se ocupe. Assim, numa só tacada, diferencia-se da barbárie popular e integra-se - ou pensa fazê-lo - à elite mundial, com a exibição de referências cultas e linguagem empolada. Mas na patuscada com as tensões entre localismo e universalismo, o que Schwarz percebe é outra coisa: as comparações não se aplicam, de fato, nem para valorizar um nem para desprestigiar o outro; antes, trazem a imagem do intelectual da periferia, o letrado colonial das classes dominantes que quer diferenciar-se do populacho e deixar de ser sócio minoritário da cultura ocidental. $\mathrm{O}$ cronista tenta defender a tradição local vendo nela elementos capazes de estar em pé de igualdade com o repertório prestigioso - e leva ao absurdo o anseio nacionalista romântico. Contudo, sua atitude produz o efeito oposto, pois, ao valorizar Martinha frente a Lucrécia sem fazê-lo nos termos da história local, acaba ocultando o mundo que pretendia revelar. Por fim, ao abandonar a moça à sua própria sorte ("Mas não falemos mais em Martinha" é a última frase da crônica), ele renega a aspiração nacional e deixa ver o lugar de classe de onde fala. Subjacentes à figura lamentável construída pela estratégia autoral, estão a razão e a culpa históricas da ambiguidade estética e política do cronista.

Além disso, na tensão entre periferia e centro o que se revela não é uma figura localista, movida a complexo de inferioridade, uma vez que seus desejos e ressentimentos compõem um quadro da história internacional, com seu cortejo de humilhações e desigualdades. "Por baixo da engrenagem retórica, lógica e estética do particular e do universal, pressionando-a e dando-lhe verdade, como um imenso subentendido, há luta de classes, luta entre nações, patamares desiguais de acumulação 
cultural, além de luta artística e crítica" ${ }^{20}$. Aqui o traço atual da crônica tal como revelado por Schwarz, a serviço da discussão dos dilemas das leituras contemporâneas em disputa sobre a maestria de Machado de Assis. Para o crítico, sob o embate de local versus universal, periferia versus centro, no século XIX e também na contemporaneidade, embora em termos diversos, configura-se uma problemática representativa que diz respeito ao lugar dos intelectuais que pensam seu país e a inserção de ambos no cenário mundializado. Universalismo e localismo são ideologias - e o que dá o teor de verdade dessa oposição não é o embate abstrato entre eles, "mas a ordem mundial desequilibrada e em litígio, de que o país faz parte. A última palavra não pertence à nação, nem à cultura hegemônica internacional, mas ao presente conflituado que as atravessa e desdiz"21.

Diferenças históricas ressalvadas, a atuação dos nossos intelectuais no período em torno de 1964 é investigada sob o prisma do esgotamento de certo ciclo mental que se constituiu no Brasil. Foi a percepção diferencial das experiências históricas no núcleo orgânico e na periferia que havia despertado e estimulado toda a tradição crítica brasileira, desde o século XIX até o esgotamento do nacional-desenvolvimentismo nos anos 1980. Com diferentes graus de autoconsciência e variadas colorações políticas, essa tradição intelectual empenhada (na acepção de Antonio Candido) dedicou-se a especificar o lugar do Brasil no concerto das nações, isto é, a entender de que maneira o país se insere no sistema econômico, político e cultural mundial, tendo em vista o objetivo de, se não suprimir, ao menos encurtar a distância que nos separava dos países que funcionaram como referência e padrão de modernidade. Em outras palavras, a norma liberal-burguesa atuava como ideologia incontornável, mesmo quando posta em crise pelo andamento da luta de classes. Para o Brasil, o raio de alcance do pensamento crítico havia sido principalmente nacional, e sempre referido ao ângulo comparativo com os países ditos desenvolvidos.

A situação mundial contemporânea, em que os países se "brasilianizaram" e passaram a apresentar realidades sociais anteriormente associadas apenas ao Terceiro Mundo, redefiniu a relação entre centro e periferia $^{22}$. Agora, o próprio horizonte de transformação parecia ter saído de cena. Com a queda do bloco socialista também a "hipótese comunista" entrava em baixa. Em âmbito nacional, a ideia desenvolvimentista de

20 MvL, p. 42.

21 Ibidem.

22 Ver ARANTES, Paulo. A fratura brasileira do mundo. In: Zero à esquerda. São Paulo: Conrad, 2004. p. 25-78. 
integração foi relegada para o campo das fantasias pias. Desapareceu a "perspectiva do progresso orientado e acelerado, fruto do conflito e da consciência coletiva" ${ }^{23}$, que havia sido a aspiração da esquerda no Brasil.

Essa situação de expectativas rebaixadas é o fundo sobre o qual o retratista desenha os vários percursos de companheiros de geração e figuras destacadas da vida intelectual que de algum modo fizeram parte, ou estiveram próximos, da esquerda - itinerários do pré-1964 aos dias de hoje, que vão da perseverança na luta anticapitalista aos diversos realinhamentos, traçados nos perfis de intelectuais reunidos no livro: Caetano Veloso, Francisco de Oliveira, Gilda de Mello e Souza, Bento Prado, Michael Löwy, Sérgio Ferro, José Arthur Giannotti. Talvez não seja despropositado, neste contexto, considerar que o próprio Roberto Schwarz é uma figura dessa galeria, pois no livro ele repassa sua própria formação intelectual e trajetória, bem como revisita seus temas centrais: as ideias fora de lugar, a obra de Machado de Assis, além de comentar o trabalho de dois de seus mestres na crítica, Antonio Candido e Adorno ${ }^{24}$.

Na entrevista "Sobre Adorno" (2003), Schwarz discute a importância da questão da atualidade no filósofo alemão e acentua o fato de ele ter criado "um modelo de discussão filosófica historicizada a partir da crise do presente" para sondar "o sentido e o destino da civilização burguesa como um todo" ${ }^{25}$. Um modelo assemelhado, desenvolvido de maneira independente, para o estudo da forma literária estava sendo elaborado por Antonio Candido, que, ao

assumir resolutamente o valor de uma experiência cultural de periferia, ao não abrir mão dela, [...] chegava a um resultado de peso, que de periférico não tem nada: a universalidade das

23 MvL, p. 177.

24. Fazer um retrato de Schwarz é tarefa que está fora de nosso alcance, mas um esboço de figura pode ser discernido no livro-homenagem organizado por CEVASCO, Maria Elisa; OHATA, Milton (org.), op. cit. Afora as exceções, que sempre existem, os textos do livro fazem emergir um retrato parcial do crítico, debuxado pelo viés de uma parte da tradição crítica brasileira, continuadora do pensamento radical no país, o qual, como notou Antonio Candido, é gerado na classe média e em setores esclarecidos das classes dominantes e, sem ser revolucionário, atua como fermento transformador (ver CANDIDO, A. Radicalismos. In: . Vários escritos. z. ed. rev. e ampl. São Paulo: Duas Cidades, 1995. p. 265-291); como Candido também lembra, na tradição cultural brasileira o contra e o a favor costumam andar misturados (ver idem, O tempo do contra. In: . Textos de intervencão. São Paulo: Duas Cidades; Ed. 34, 2002. p. 369-379).

25 MvL, p. 45 e 49. 
categorias dos países que nos servem de modelo não convence e a sua aplicação direta aos nossos é um equívoco. ${ }^{26}$

A partir do paralelo entre Candido e Adorno, Schwarz afirma que “o ensaísmo periférico de qualidade sugere a existência de certa linearidade indevida nas construções dialéticas de Adorno e do próprio Marx"27. Trata-se, também aqui, de desconfinar a experiência periférica de seu alcance apenas local, bem como de desconfiar da infalibilidade do ponto de vista central.

A experiência social que impulsionou a tradição crítica brasileira, de que Antonio Candido é figura central, adensou-se nos anos anteriores ao golpe militar, a que se ligam os intelectuais retratados em Martinha versus Lucrécia. Entre todos, é o perfil de Caetano Veloso, em "Verdade tropical: um percurso de nosso tempo", que explicita o núcleo da reflexão de Schwarz sobre a experiência de 1964 e seus desdobramentos. Nesse ensaio, o crítico ressalta a grande qualidade literária do panorama construído pelas memórias e reflexões de um "intelectual de envergadura", em que as correspondências entre vida pública, vida privada e criação artística, bem como domínio de um setor fundamental na cultura contemporânea (a música popular) e avaliações críticas ousadas compõem um conjunto com vigor e significado incontornáveis. A força de Verdade tropical (1997) talvez esteja, de início, no frescor com que Caetano rememora a rebeldia de um grupo de jovens provincianos, que de provincianos tinham pouco, e no qual ele desponta. Mas ela ganha maior interesse no desacordo entre as duas primeiras partes e as seguintes, quando as dissensões de Caetano com a esquerda especialmente após o golpe deixam ver o afastamento em relação aos ideais que congregavam setores variados no pré-1964, de socialistas a nacionalistas e cristãos de esquerda, quando não simplesmente das pessoas esclarecidas, campo com o qual o compositor estivera afinado.

Magistralmente recortada por Schwarz, ganha significado emblemático a interpretação que Caetano dá à cena de Terra em transe (1967) de Glauber Rocha, em que Paulo Martins, o intelectual de origem oligárquica convertido à revolução, exasperado pelas ambiguidades das lideranças populistas e pela passividade da massa, tapa a boca de um líder sindical e se dirige ao público, dizendo que o povo "é um analfabeto, um imbecil, um despolitizado!". Para Schwarz, a truculência da personagem revela, entre outras coisas, "a dubiedade do intelectual que

26 MvL, p. 49.

27 Ibidem. 
se engaja na causa popular ao mesmo tempo que mantém as avaliações conservadoras - raramente explicitadas como aqui - a respeito do povo" ${ }^{28}$. No contexto do filme, isso levará o protagonista à aventura da luta armada sem apoio social. Vale a pena a citação de trecho da análise do crítico sobre a cena:

Do ponto de vista da esquerda, a cena - uma invenção artística de primeira força - era um compêndio de sacrilégios, fazendo uma espécie de chacota dolorosa das certezas ideológicas do período. Os trabalhadores estavam longe de ser revolucionários, a sua relação com os dirigentes pautava-se pelo paternalismo, os políticos populistas se acertavam com o campo adversário, a distância entre as teses marxistas e a realidade social era desanimadora, e os intelectuais confundiam as razões da revolução política e as razões da realização pessoal. Nem por isso se atenuavam as feições grotescas das camadas dirigentes e da dominação de classe, que se encontravam de pé, esplendidamente acentuadas. A revolução não se tornara supérflua, muito pelo contrário: encontrava-se num beco histórico e não dera o necessário passo à frente. A nota geral era de desespero. ${ }^{29}$

Caetano Veloso, porém, leu dramaticamente uma cena de construção épica, sem levar em conta o efeito de distanciamento assim produzido e a personalidade problemática de Paulo Martins. Leu-a como a declaração de morte do populismo, atribuindo-lhe sentido peculiar: a morte da fé nas forças populares. Um novo tempo se anuncia para o jovem que já fora rebelde, "um tempo em que a dívida histórico-social com os de baixo - talvez o motor principal do pensamento crítico brasileiro desde o Abolicionismo - deixou de existir"30. Trata-se de um tempo de desobrigação, quando certas parcelas de nossa intelligentsia deixaram de se orientar por um horizonte de transformação socialista.

O movimento regressivo se inscreve em mais uma equivocada avaliação de Caetano: a liberdade trazida pelo Tropicalismo, sem as injunções "opressivas" (sic) da esquerda, é o que ele considerava o novo na representação do país, mas "as miradas críticas de natureza antropológica, mítica, mística, formalista e moral", segundo o registro de Verdade tropical, de fato remetiam ao velho. O futuro, tal como o

\footnotetext{
28 MvL, p. 76.

29 MvL, p. 77.

zo MvL, p. 79 .
} 
entendia Caetano, requenta fórmulas do passado que, rearranjadas e radicalizadas por figurinos contemporâneos, são capazes, entretanto, de capturar os tempos presentes, compondo a conversão da ideia de Brasil em mercadoria. Querendo-se à esquerda da esquerda, que considerava moralista e tacanha, Caetano abalava establishments e resguardava o mercado. Tachando como retrógradas as questões que haviam mobilizado as inteligências em torno de 1964, a saber, a análise de classes, a crítica ao capital e ao imperialismo, bem como a desmistificação do produto pitoresco que constituía a nação, Caetano fazia tabula rasa das conquistas que haviam se alçado ao primeiro plano naqueles anos de luta por transformação.

No curso da história contemporânea, a avaliação do músico ganha de fato verdade, não só tropical, e emblematiza percursos predominantes em nosso tempo, quando muitos se rendem à voragem mercantil, ou, em mão contrária, não levam adiante a crítica ao fetichismo da mercadoria. É preciso investigar o porquê disso. Para Schwarz, atento à pouca coerência entre as partes do livro - defeito estético que atua como sintoma relevante -, cabe ressaltar que a incongruência visível das posições pode refletir a correlação de forças pós-golpe, em que talentos e inteligências operam uma conversão histórica representativa que encontra em Caetano uma figura histórica exemplar.

Quando surgiu o Tropicalismo, Schwarz identificou nele uma manifestação cultural significativa na medida em que formalizava no plano estético a sensibilidade nova que impregnava aqueles jovens: era a primeira geração a crescer em familiaridade estreita com a cultura de massa, que se afastava da esquerda nacionalista, e para quem a afirmação nacional contra o Imperialismo havia se tornado um tópico vazio $^{31}$. Para a geração tropicalista, a identidade nacional se assimilava precisamente à dualidade brasileira característica, só que, agora, sem feição negativa e sem ser acompanhada de intuito superador. Longe de ser, como fora até então, um estado de coisas a recusar (e a se ultrapassar no futuro), a mistura de traços modernos e arcaicos é convertida em imagem da própria identidade brasileira ${ }^{32}$. O sucesso de Caetano deve-se

31 Cf. SCHWARZ, R. Cultura e política, 1964-1969. In: O pai de família e outros estudos. Rio de Janeiro: Paz e Terra, 1978.

32 Se no Modernismo oswaldiano e na produção cultural dos anos 1950-1964, os vexames nacionais com relação à integração das populações ganhavam lugar formal com vistas à transformação política (MvL, p. 101), com o Tropicalismo eles retornam - inspirados também em Oswald de Andrade - para, no entanto, validar o Brasil da contrarrevolução e sua combinação de modernização capitalista e reposição do atraso social. A convergência, anterior ao golpe, entre inovação artística e dessegregação social avivava o desejo, talvez ilusório, de alcançar uma sociedade inte- 
à eficácia com que sua arte apreende na primeira hora a novidade ideológica do período e a expressa a partir da experiência cotidiana em que ganhavam novo sinal as conjunções entre progresso e atraso, norma e informalidade, desajustes e descompassos entre formas modernas e a realidade prática brasileira. É a manifestação inicial de uma interpretação do país que não mais se articula a um projeto de construção futura, indicando em chave celebratória que "a hipótese de uma articulação histórica em plano superior saíra de cena" ${ }^{\text {`z }}$. Segundo o crítico, o Tropicalismo apresenta, com distanciamento, um ponto de vista afinado com o da contrarrevolução triunfante, sendo, por isso mesmo, estética e ideologicamente significativo. A conversão da dualidade em emblema nacional comerciável faz pensar num achatamento da temporalidade, pois o progresso não é mais assimilado a um futuro vindouro, e os traços arcaicos deixam de ser identificados a resquícios do passado e são vistos como rigorosamente contemporâneos. Nisso havia um grão de verdade, pois o atraso era de fato um resultado moderno; contudo, ele encerra também um momento de falsidade, ao se escamotear o caráter problemático daquela dualidade, que exige análise nos termos da divisão de classes interna e internacional, bem como a ativação de um novo projeto transformador.

O percurso de parcela significativa da esquerda após a derrota de 1964 encontra expressão em Verdade tropical, em que o relato - especialmente após a prisão de Caetano, seu exílio e retorno ao Brasil vale como documento histórico, menos por constituir um bem tramado compósito de memórias e reflexões, e mais por dar testemunho de uma representativa trajetória de acomodação à ordem vencedora, de que faz parte certo tipo de rebeldia ("muito à vontade no atrito mas avesso ao antagonismo propriamente dito" $\left.{ }^{34}\right)$. Por isso, a melhor maneira de aproveitar a obra de Caetano implica boa dose de leitura a contrapelo; a despeito da interpretação que o próprio autor dá aos fatos, pode-se entrever no relato a "dramatização histórica" de um momento crítico da vida brasileira: "de um lado o interesse e a verdade, as promessas e as deficiências do impulso derrotado; do outro o horizonte rebaixado e inglório do capital vitorioso"35. Mais do que apontar apenas uma guinada na posição política, o rumo posteriormente tomado por aquela geração acabaria dando

grada. Contudo, com a derrota do campo popular, esses impulsos "adquiriam uma nítida nota escarninha, inclusive de autoderrisão, aliás indispensável à verdade do novo quadro" (MvL, p. 95-96).

34 MvL, p. 65.

35 MvL, p. 110. 
a conhecer a convergência entre parte do ideário da esquerda e o curso do capital.

Nesse sentido, é sugestivo o comentário do crítico norte-americano Nicholas Brown, que retoma observações de "Cultura e política, 1964-1969" e é parafraseado por Schwarz:

a vitória da contrarrevolução em 1964-70, com a decorrente supressão das alternativas socialistas, havia propiciado a passagem precoce da situação moderna à pós-moderna no país, entendida esta última como aquela em que o capitalismo não é mais relativizado por um possível horizonte de superação. ${ }^{36}$

Para Schwarz, o que explica esse entendimento de que o Tropicalismo pode ser visto como um movimento que antecipa a ordem pós-moderna é o fato de ele expressar as consequências da virada do país à direita, tendo "nascido já no chão da derrota do socialismo" ${ }^{37}$. Sem o saber, estávamos na vanguarda. A modernização promovida pela ditadura militar não levou à crítica recíproca entre as culturas tradicional e moderna; o que se deu foi apenas a sua junção "nos termos lamentáveis das conveniências do mercado"38, donde se vê o interesse das questões suscitadas pelo percurso vitorioso de Caetano.

Perdedores, porém, há vários. Renitentes, também. Posições ambivalentes não faltam. Mas se mantêm os que permanecem no campo da intervenção, política ou estético-política, em que a atuação e a criação se põem a serviço da leitura de alguns dos impasses contemporâneos, não se deixando enganar pelo progresso de fachada e reinventando modos de figurar traços recorrentes de nossa sociabilidade.

A atualidade do vínculo entre informalidade e norma, na perspectiva do país periférico, é o que norteia os ensaios "Um minimalismo enorme" (2002), sobre Elefante (2000), de Francisco Alvim, e "Cetim laranja sobre fundo escuro" (2009), sobre Leite derramado (2009), de Chico Buarque. Em Francisco Alvim, Schwarz analisa a maneira pela qual o poeta coleciona despropósitos nacionais, atento aos enunciados sociais de nossa fala cotidiana. Há algo nessa escuta que dá prosseguimento à tradição dos modernistas e de algum modo é parente da empresa tropicalista, sem celebrar, contudo, a junção de disparidades. A matéria brasileira subjaz nos conteúdos dos poemas e os une numa totalidade

36 MvL, p. 79 .

37 MvL, p. 8 o.

$3^{8}$ Fim de século. In: Sequências brasileiras. op. cit., p. 159. 
implícita: consiste naquele vínculo, no qual atua como variante nova a experiência da ditadura militar e o bloqueio das perspectivas de superação do fundamento sociopolítico da informalidade, a saber, a falta de direito dos pobres, a integração precária, a feroz fratura social. Além disso, apesar da familiaridade que temos com os enunciados sociais à brasileira, seu recorte e montagem provoca um estranhamento de efeito cômico-grotesco. Nessa direção, aqueles traços de informalidade não são marcas do atraso; a perplexidade que provocam se intensifica porque são contemporâneos. No mundo homogeneizado em muitos aspectos, o Brasil é o elefante que atravessa os tempos, em que "o passado não passou, embora já não ajude - como ainda outro dia - a inventar o futuro, que não está à vista" ${ }^{39}$. No momento em que a questão nacional não é mais tensionada pelo impulso transformador, a obra de Francisco Alvim registra a face renovada de "nossa pesada herança político-moral" Talvez por não se prestarem à comicidade irônica, não são ouvidas outras falas que capturam as feições mais brutais da sociabilidade contemporânea e o alto grau da violência direta. Esse, talvez, o limite da forma, mas Schwarz não trata dele, pois seu fio de continuidade é outro: uma das urgências da tarefa crítica consiste em "reencontrar no presente a conexão com as contradições antigas e irresolvidas"

O opressivo legado político-moral, que interessa ao crítico analisar, continua a atuar nos remanescentes das antigas formas de dominação, como Schwarz mostra com sua leitura de Leite derramado, em que o autor, Chico Buarque, põe para falar o velho moribundo que, a despeito de sua situação miserável no presente, ainda se arroga as pretensões do mando. Com o palavrório interminável de Eulálio Assumpção e a descontínua rememoração de sua extensa história familiar, exibe-se o verdadeiro protagonista do romance: a contemporaneidade, cujas desgraças põem o passado em perspectiva e ditam o olhar de nossas elites senhoriais, que, mesmo arruinadas, nunca acabam de morrer. $\mathrm{O}$ passado patriarcal ao mesmo tempo se opõe ao presente e o prefigura e desqualifica. Mudaram os tempos, decerto, mas o relato de Eulálio, misturando com extravagância a exibição da glória anterior (negócios infames, corrupção) à perda das prerrogativas de classe e à descendência obscura, faz um tempo se refletir sobre outro, embaralhando o senso comum a respeito do progresso - por exemplo, negociatas que mudam de lugar (com novos tráficos a explorar, como o faz seu tetraneto). Protótipo de setores atrasados da antiga classe

39 MvL, p. 136.

40 MvL, p. 142.

$41 \quad$ MvL, p. 227. 
dominante que não conseguiu atualizar-se para continuar a dominar, Eulálio segue repetindo preconceitos e perversidades bem atuais. O país que não se formou, e que se integra à ordem mundial produzindo novas versões da informalidade e do abuso, continua a gerar mortos-vivos, injustiças e deformidades.

Schwarz nota em Leite derramado uma série de paralelos com situações machadianas, em particular com Dom Casmurro, e outros chegaram mesmo a descobrir no romance de Chico Buarque um amplo reaproveitamento dos achados da tradição crítica brasileira ${ }^{42}$ - no caso, com destreza literária. Aqui, porém, o reaproveitamento parece sugerir um espelhamento entre a crítica e a ficção que sinaliza a rotinização dessa tradição, bem como a perda de seu fermento crítico para tratar de particularidades sociais contemporâneas e municiar a criação artística para a observação de novos materiais. A questão, contudo, não é objeto da exposição de Schwarz, para quem o valor da obra parece ser o modo como ela dá a ver a permanência da estrutura de iniquidades, fundamento tanto da tradicional truculência autoritária quando da informalidade familiar, também tradicionalíssima, hoje em suas novas dimensões. Assim, a experiência contemporânea apreendida pelo romance repetiria a "comédia brasileira", mas dessa figuração escapam as novas formas de dominação, que o personagem-narrador não apanha, medusado que está pelo próprio passado.

Contra os fantasmas que seguem reproduzindo os fundamentos socioeconômicos da "inorganicidade" do país, para usar o termo de Caio Prado, assomam na coleção de perfis os intelectuais que atuaram em, ou ao menos simpatizaram com os projetos de transformação que rondaram o final dos anos 1950 e início dos anos 1960 e apostavam na dinamização geral que estava em curso. Se não for abusado nos valermos livremente de um comentário de Schwarz, a respeito de nomes diversos da música popular brasileira, aqui "as figuras individuais somam, ressoando umas nas outras e configurando com densidade a problemática de uma geração" ${ }^{\text {43 }}$.

Se no plano da realização literária fica evidenciada, nos ensaios sobre os dois Franciscos, a permanência de certas relações na vida atual, torna-se imprescindível, contudo, verificar as redefinições categoriais pertinentes ao processo contemporâneo, sob pena de empregar fórmulas

42 Ver MORAES, Reinaldo. Leite derramado: memórias quase póstumas de Chico Buarque. JB Online, 20 mar. 2009, em que o autor identifica, no romance, a ressonância de interpretações clássicas sobre o Brasil, de Gilberto Freyre, de Sérgio Buarque e do próprio Roberto Schwarz.

43 MvL, p. 73. 
que, repetidas à exaustão, podem obstar a investigação de aspectos novos do presente: "as contradições com que o progresso vem surpreendendo os seus adeptos socialistas são a substância de nossa experiência contemporânea e a matéria em relação à qual é preciso progredir"44. Por isso, "Saudação a Sérgio Ferro" (2005) e "Um jovem arquiteto se explica" (2002), textos em que Schwarz trata da arquitetura, entendida como ponto de encontro das várias dimensões da vida social e, portanto, como potencial "modelo para um debate estético realmente vivo"45, propiciam extraordinária aprendizagem sobre os impasses a que chegou o projeto desenvolvimentista e os riscos da retomada do encontro entre intelectuais de esquerda e as populações pobres sem o exame histórico-sociológico da experiência de finais dos anos 1960. Sem a crítica rigorosa das relações de produção, o anseio da aliança de classe pisa em falso, e reativam-se as ilusões, ainda que progressistas.

Compreender o movimento crítico gestado no pré-1964 bem como levar a cabo a crítica de suas potencialidades, de seus erros e acertos, é ainda tarefa de nosso tempo. A experiência do golpe e de suas consequências permanece como trauma objetivo, não elaborado, óbice que dificulta a compreensão do presente. Um monumento em torno do qual transitam batalhões de homens formados na tradição da esquerda que acabaram por se alinhar entre os vencedores, qualificados "para participar, em posição saliente, no curso normal da sociedade contemporânea"46.

Em outra via, os retratos de Gilda de Mello e Souza e Bento Prado, bem como no de Michael Löwy, evidenciam as várias nuances da não adesão ao movimento vitorioso. Esses intelectuais insistiram na perspectiva crítica, cada um à sua maneira. Em "Gilda de Mello e Souza" (2006 - 2007), Schwarz comenta ensaios em que ela analisa obras artísticas de teor político direto e aponta o preço pago pela simplificação, mistificadora por vezes. Atenta às armadilhas da criação artística, Gilda acompanhava com rigor o movimento da forma, que não raro desmentia as intenções autorais, e apreendia, quase profeticamente, o que a história posterior acabaria por confirmar.

Em "Aos olhos de um velho amigo" (2007), Schwarz relembra, entre histórias saborosas, a rebeldia programática de Michael Löwy e como ela pode e deve ser compreendida na contracorrente das visões tradicionalistas da ação política do período, opondo-se a uma interpretação etapista e nacionalista. Schwarz assinala que a série de movimentos sociais nos

44. MvL, p. 226.

45 MvL, p. 231.

46 MvL, p. 221, grifo do autor. 
países periféricos até os anos 1970 dava a impressão de confirmar o acerto da teoria da revolução permanente; mas, no período subsequente, a construção da sociedade socialista encontrou obstáculos de que essa teoria não deu conta.

O mesmo bloqueio do socialismo é o que explica a engenhosa leitura de Marx empreendida por José Arthur Giannotti. Em "O neto corrige o avô" (2001), o empenho de contenda do ensaísta reaparece, desde o subtítulo ("Giannotti vs. Marx"). Schwarz recapitula a iniciativa do filósofo de ler $O$ capital numa perspectiva estrutural, novidade à época, reunindo o grupo que formaria o "Seminário Marx". Essa postura avançada do professor de lógica teve também consequências políticas, na medida em que batia de frente com a leitura doutrinária do Partido Comunista Brasileiro. Desse grupo nasceram os trabalhos que procuraram incorporar, no âmbito acadêmico, o fundo conflitivo da luta de classes por meio da investigação de aspectos específicos da sociedade brasileira. No entanto, em seu livro Certa herança marxista, Giannotti corta a dimensão política do marxismo e a crítica do fetichismo, reduzindo o modo de produção capitalista a uma gramática das relações de trabalho. O terreno acadêmico parece ter vencido, e a verve política aliouse a uma desistência da análise crítica da ordem mundial triunfante, ou, antes, para a afirmação de que o socialismo não apenas é inviável como perigoso.

Rumo diverso é o de Francisco de Oliveira, sobre o qual Schwarz destaca pontos cruciais das investigações do sociólogo no livro Crítica da razão dualista (1972), republicado trinta anos depois com o acréscimo do ensaio "O ornitorrinco" (2003), que coloca em perspectiva a análise anterior ("Prefácio a Francisco de Oliveira, com perguntas", de 2003). Também aqui a discussão passa pelas promessas de integração futura, com seu quê desenvolvimentista, ainda discretamente presentes no texto de 1972, e a análise dos fundamentos econômicos do "neoatraso" trinta anos depois, quando já não há resquício de ilusões superadoras. Entre um momento e outro, ocorreram o anticlímax da falência do nacionaldesenvolvimentismo e o esgotamento de um ciclo histórico que deixou um rastro de promessas não cumpridas, dando lugar a circunstâncias novas, cujas razões econômicas "O ornitorrinco" busca explicitar. O estudo de Oliveira procura compreender o presente por meio do exame dos novos mecanismos econômicos que conduziram à "informalização do trabalho" e à "desconstrução da relação salarial", bem como à “formação de uma nova classe social no país" ${ }^{47}$. No plano da política,

47 MvL, p. 153-154. 
assistiu-se ao reencontro de setores políticos que a luta contra a ditadura havia unido, e que os anos de redemocratização dividiram num "antagonismo partidário-eleitoral entre esquerda e centro-direita"; mas esse reencontro se deu de acordo com a pauta ditada pelas "necessidades [...] antissociais do capital"48. Nas novas circunstâncias, em que governar se reduz a intermediar os interesses do mercado, com as consequentes desgraças no campo social, a sociedade brasileira “já não é subdesenvolvida, não porque se desenvolveu, mas porque deixou de ser tensionada pelo salto desenvolvimentista; e [...] não é desenvolvida, pois continua aquém da integração social civilizada"49. Assim, mostra-se como a “exceção permanente" ${ }^{50}$ do sistema capitalista na periferia.

"O ornitorrinco" é o resultado de algo que, dez anos antes, Schwarz havia identificado no trabalho de Oliveira, o esforço de "conceber as redefinições impostas pelo processo em curso, que é preciso adivinhar

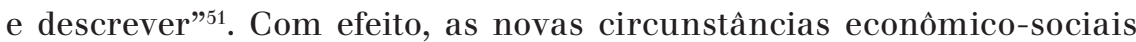
analisadas pelo sociólogo abalam as conceituações e esquemas interpretativos anteriores, o que ressoa no andamento das categorias no ensaio. À luz da atualidade, não é possível ignorar a nova tendência ou "a data vencida de convicções que estão na praça”, mas também não há como não notar que o presente e o futuro não são superiores às "formas ou aspirações que perderam o fundamento" ${ }^{52}$.

Talvez seja nesse texto que Schwarz mais se aproxima da continuidade da reflexão iniciada em Sequências brasileiras, e não por acaso. Como o próprio Francisco de Oliveira reconheceu, "O ornitorrinco" deve muito a "Fim de século"55. O diagnóstico de Oliveira sobre a atual sociedade em desagregação explicita os fundamentos materiais das peculiaridades do novo ciclo, que já vinham aparecendo em obras como Estorvo e Cidade de Deus, ambas estudadas no livro anterior de Schwarz, e mencionadas em entrevista incluída em Martinha versus Lucrécia ${ }^{54}$. A esses dois romances acrescenta-se o filme Cronicamente inviável (2000), de Sérgio Bianchi, que apreende os "resultados não programados da abertura econômica de Collor"55, com trabalhadores desmoralizados, burguesia ressentida, ambos lumpenizados, e brutalidades a perder de vista.

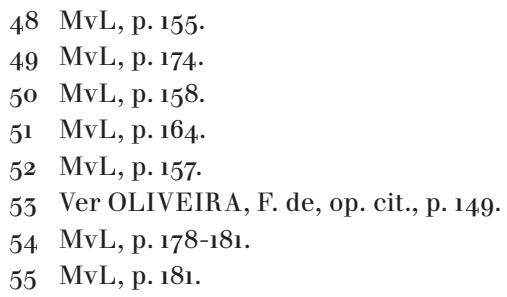


Para Schwarz, o momento atual de decomposição das promessas mas também das ilusões - do ciclo anterior pode levar a "uma espécie de atualismo curto", talvez, imaginamos, afinado com o sentimento de urgência que vigora hoje, preenchendo o vazio deixado pela atrofia da política. Alternativamente, trata-se também de um momento propício à "memória da experiência feita" ${ }^{56}$, que sofreu desautorização histórica. A propósito, cabe lembrar que, diante dos resultados da modernização capitalista que levaram, não ao completamento, mas à falência dos projetos de construção do país, e que pareciam rifar a reflexão atrelada à referência nacional, Schwarz discutia, em ensaio de 1998, o destino da própria ideia de formação, bem como indicava que "a contemplação da perda de uma força civilizatória não deixa de ser civilizatória a seu modo" 57 . Em Martinha versus Lucrécia, o crítico realiza um movimento semelhante a "uma prestação de contas teórica e uma auto-historicização, em linha com o propósito de trabalhar por formas de consciência expandida" ${ }^{58}$, examinando a experiência política e intelectual de uma geração. Com foco em 1964 e seus desdobramentos atuais, a análise se detém em um grupo circunscrito de personalidades, estimulando a reflexão sobre o que se formou e o que se desmanchou naqueles anos. Disso decorre a necessidade de reacender a imaginação política, agora não mais restrita ao quadro nacional, mas voltada para a crítica do sistema capitalista no seu todo, visando à reestruturação, ou a uma verdadeira formação, da sociedade em termos novos, em parte ainda a serem inventados.

Em “Agregados antigos e modernos”, Schwarz assinala as novas formas da destrutividade social do capitalismo "no contexto da vitória avassaladora do capital sobre os movimentos operários, carregada de consequências sociais regressivas, entre as quais uma certa desmoralização de alto a baixo, proveniente da nova unilateralidade"59. As condições atuais de despolitização e de administração da pobreza, bem como de outras consequências da ordem mundial, resultantes da globalização e das políticas de governamentalidade a elas articuladas, criam nova ordem de marginalizações, ampla desagregação social, cujo fim não está à vista. Por isso, a continuidade das reflexões materialistas de Schwarz exige que se busquem as consequências do que elas já nos fizeram compreender e apreender. Exigem que se procurem, nas formas objetivas e nas formas artístico-culturais, ângulos que permitam a

56 MvL, p. 158.

57 Os sete fôlegos de um livro. In: Sequências brasileiras. op. cit., p. 58.

58 MvL, p. 159. Utilizamos livremente uma formulação de Schwarz, referente a Francisco de Oliveira.

59 MvL, p. 176. 
reinvenção das categorias, sem perder o gume da crítica, e contribuam para elucidar a novidade da dinâmica econômico-social contemporânea. No atual apartheid em que o mundo está imerso, perversas formas de integração se globalizam - e, com a vitória do inimigo e das ideias que até há pouco eram seus oponentes, os mortos continuam a se acumular. Novas modalidades de integração dos pobres, que reduzem a miséria mas não promovem a autonomia, de um lado, e práticas punitivas de repressão e encarceramento (quando não de puro extermínio), de outro, ocupam o lugar da política propriamente dita, ao mesmo tempo que a imaginação política definha ao perder o horizonte da superação socialista. "A reconfiguração geral do capitalismo, de que 64 fez parte, exige uma resposta que os socialistas continuam devendo" ${ }^{\circ}$. Retomando aquilo que foi lançado ao esquecimento e tratando de 1964 como "uma aula do que não muda no Brasil" ${ }^{1}$, Roberto Schwarz nos instiga a nos lançarmos na análise incisiva do que persiste e do que é a novidade do contemporâneo, ainda não conceitualizada.

6 o MvL, p. 89 .

61 "A dialética envenenada de Roberto Schwarz", cit. 